\title{
Clostridium hydroxybenzoicum sp. nov., an Amino Acid- Utilizing, Hydroxybenzoate-Decarboxylating Bacterium Isolated from Methanogenic Freshwater Pond Sediment
}

\author{
XIAOMING ZHANG,${ }^{1} \dagger$ LINDA MANDELCO, ${ }^{2}$ AND JUERGEN WIEGEL ${ }^{1 *}$ \\ Department of Microbiology and Center for Biological Resource Recovery, University of Georgia, Athens, Georgia \\ $30602^{1}$ and Department of Microbiology, University of Illinois at Urbana-Champaign, Urbana, Illinois $61801^{2}$
}

\begin{abstract}
Clostridium hydroxybenzoicum JW/Z-1 ${ }^{\mathrm{T}}(=$ ATCC 51151 = DSM 7310) $)(\mathrm{T}=$ type strain $)$, isolated from freshwater pond sediment, is a nonmotile, gram type-positive, spore-forming, amino acid-utilizing, anaerobic rod. This bacterium produces two inducible enzymes that catalyze the decarboxylation of para-hydroxybenzoates. The phenols produced are not utilized. $C$. hydroxybenzoicum requires yeast extract for growth. Sugars are not utilized. Sodium ions and acetic acid stimulate growth. The optimal temperature and optimal pH for growth are 33 to $34^{\circ} \mathrm{C}$ and 7.2 to 8.2, respectively. The DNA base composition of the type strain is $35.5 \mathrm{~mol} \%$ guanine plus cytosine, whereas the DNA base compositions of the type strains of Clostridium sticklandii and Clostridium aminovalericum are 33 and $33.5 \mathrm{~mol} \%$ guanine plus cytosine, respectively, as determined by a chemical method. 16S rRNA sequence analysis groups strain JW/Z-1 ${ }^{\mathrm{T}}$ most closely with Clostridium purinolyticum and Clostridium acidiurici (10.6 and 11 inferred changes per 100 bases, respectively). However, $C$. hydroxybenzoicum does not utilize uric acid, hypoxanthine, xanthine, adenine, or guanine. The cell wall type is A1 $\alpha$ (L-Lys direct).
\end{abstract}

Various aromatic compounds, either of natural origin or of anthropogenic origin, can be transformed and mineralized in various anaerobic environments $(4,12,14-16,41,43)$. Hydroxybenzoate is one of the key aromatic intermediates in the anaerobic degradation of the biopolymer lignin, its hydrolytic products, and similar aromatic compounds. In a previous study of the anaerobic degradation of 2,4-dichlorophenol, we found that mineralization of 2,4-dichlorophenol to methane and carbon dioxide in a freshwater sediment sample required the sequential action of at least five different bacteria (45). During additional studies, a phenol-degrading enrichment culture was established, from which Clostridium sp. strain JW/Z-1 $1^{\mathrm{T}}(\mathrm{T}=$ type strain) was isolated (44). This bacterium decarboxylates 4-hydroxybenzoate and 3,4-dihydroxybenzoate to phenol and catechol, respectively. In this paper we describe additional properties of this organism and propose that strain JW/Z-1 ${ }^{\mathbf{T}}$ be the first member of the new species, Clostridium hydroxybenzoicum.

\section{MATERIALS AND METHODS}

Organisms and media. $C$. hydroxybenzoicum $\mathrm{JW} / \mathrm{Z}-1^{\mathrm{T}}$ was isolated from a freshwater sediment sample in Athens, Ga. (44). Clostridium aminovalericum ATCC $13725^{\mathrm{T}}$ and Clostridium sticklandii ATCC $12662^{\mathrm{T}}$ were obtained from The American Type Culture Collection, Rockville, Md.

ATCC medium 1626 (1) was used to grow $C$. aminovalericum. C. sticklandii and C. hydroxybenzoicum were grown in mineral medium (44) supplemented with $1 \%$ yeast extract, $0.1 \%$ glycine, $0.1 \%$ L-arginine, and $0.1 \%$ L-lysine or in other media (see below).

To test whether the growth of $C$. hydroxybenzoicum was stimulated in the presence of $10 \mathrm{mM}$ adenine, hypoxanthine, uric acid, guanine, or xanthine, mineral basal medium contain-

* Corresponding author. Phone: (706) 542-2651. Fax: (706) 5422674. Electronic mail address: jwiegel@uga.cc.uga.edu.

$\dagger$ Present address: EPA Environmental Research Laboratory, 960 College Station Road, Athens, GA 30605-2720. ing $0.3 \%$ yeast extract and $0.1 \%$ glycine was used. Peptoneyeast extract medium supplemented with $20 \mathrm{mmol}$ each of glycine and L-lysine per liter was used to grow cells for the lipid fatty acid analysis (gas chromatography of fatty acid methyl esters [Microbe Inotech Laboratories, Inc., St. Louis, Mo.]).

Tests involving cell suspensions. $C$. hydroxybenzoicum was grown in mineral medium supplemented with $1.5 \%$ yeast extract and $10 \mathrm{mM}$ each of glycine, L-arginine, and L-lysine. Cells were harvested anaerobically by centrifugation. The resulting cell pellet was suspended in prereduced mineral medium ( $\mathrm{pH} 7.0)$ without yeast extract or any other carbon and energy source to an optical density at $600 \mathrm{~nm}$ of 1.0 to 1.3 . Incubation was started after $10 \mathrm{mmol}$ of glycine, L-arginine, or L-lysine or combinations of these amino acids per liter was added to the suspensions. Each preparation was incubated for $22 \mathrm{~h}$ at $30^{\circ} \mathrm{C}$, during which time the optical density decreased by $10 \%$ because of lysis of some cells.

Tests involving growing cultures. Gelatin hydrolysis, indole production, and sulfide production were tested as described by Smibert and Krieg (32).

Fermentation products. Volatile fatty acids were determined by gas chromatography as described previously (44). Acetic acid was determined enzymatically by using reagent kit 148-261 obtained from Boehringer Mannheim GmbH, Mannheim, Germany.

Amino acid determination. Amino acids were analyzed as dansyl amino acid derivatives by using the methods of Kaneda et al. (19) and Bayer et al. (3). Dansylation was performed by the method of Tapuhi et al. (34). A 6- $\mu$ l portion of a sample was added to $400 \mu \mathrm{l}$ of $100 \mathrm{mM} \mathrm{NaHCO}$. In cell suspension tests, $4 \mathrm{mmol}$ of valine per liter was added to the $\mathrm{NaHCO}_{3}$ solution as the internal standard. A 200- $\mu$ l aliquot of a 5-dimethylaminonaphthalene-1-sulfonyl chloride solution (6 $\mathrm{mg} / \mathrm{ml}$ of acetonitrile) was added to start the reaction. The sample was incubated at $60^{\circ} \mathrm{C}$ for $10 \mathrm{~min}$ in the dark, vortexed for $2 \mathrm{~min}$, and then centrifuged for $10 \mathrm{~min}$. The supernatant from the sample was stored at $-20^{\circ} \mathrm{C}$ until it was analyzed. A 50- to 100- $\mu$ l portion of the supernatant was injected into a C18 high-performance liquid chromatography column. The 
two running solvents used were $100 \%$ methanol (solvent A) and $30 \%$ methanol-70\% $100 \mathrm{mM}$ Tris- $\mathrm{HCl}$ buffer $(\mathrm{pH} \mathrm{7.75)}$ (solvent B). A linear gradient was made by increasing the proportion of solvent B in a solvent A-solvent B mixture from 5 to $25 \%$ at a rate of $0.5 \% / \mathrm{min}$ and then increasing the proportion of solvent $\mathrm{B}$ at a rate of $2 \% / \mathrm{min}$ until the proportion of solvent B was $95 \%$. The flow rate of the mobile phase was $1.0 \mathrm{ml} / \mathrm{min}$. The wavelength used for detection was $254 \mathrm{~nm}$.

Electron microscopy. Transmission electron microscopy was performed with a model JEM-100 CXII electron microscope (JEOL, Tokyo, Japan). Samples for ultrathin sectioning were prepared as described previously $(20,33)$, and uranyl acetate and lead citrate were used for poststaining (13).

Cell wall analysis. Cell walls were prepared and peptidoglycan structure was determined by using the methods described by Schleifer and Kandler (30). Amino acids and peptides were separated and characterized by thin-layer chromatography on cellulose sheets.

Sequence analysis of $16 \mathrm{~S}$ rRNA and data analysis. Total RNA was isolated from $C$. hydroxybenzoicum $\mathrm{JW} / \mathrm{Z}-1^{\mathrm{T}}$ by using a customary procedure $(22,38,39)$. A combination of dideoxynucleotide chain termination and reverse transcriptase (5, 21, 29) was used. The synthesized DNA strands were labeled with thio- ${ }^{35}$ S-labeled dATP (5). A standard set of primers specific for (eu)bacterial 16S rRNAs was used (36). The sequences were aligned by using sequence editor ae 2 (C. R. Woese, University of Illinois) and a representative collection of (eu)bacterial 16S rRNAs $(26,28)$. Corrected pairwise distances (expressed as the estimated numbers of changes per 100 nucleotides) were computed from percentages of similarity (1,286 nucleotides were compared) by using the Jukes-Cantor correction (18) as modified by G. J. Olsen (36) to accommodate the actual nucleotide ratios. Dendrograms were constructed from evolutionary distance matrices by using the algorithm of De Soete (9).

\section{RESULTS}

Many morphological and physiological properties of strain $\mathrm{JW} / \mathrm{Z}-1^{\mathrm{T}}$, including its characteristic decarboxylation of parahydroxybenzoate and analogous compounds, have been described previously $(42,44)$. A further description of the characteristics of this organism is given below, mainly to provide a basis for comparison with similar organisms.

Cell wall structure and type. $C$. hydroxybenzoicum cells, rods with pointed ends, exhibited the typical cell wall structure of gram-positive organisms (Fig. 1). The cell wall type was $\mathrm{A} 1 \alpha$ (L-Lys direct) (36a).

Lipid fatty acid composition. The following fatty acid methyl esters were found: $12: 0(2.1 \%), 14: 0(18.4 \%), 16: 1$ cis-7 $(2.2 \%)$, $16: 1 \mathrm{cis}-9(10.7 \%), 16: 0(9.0 \%), 18: 1 \mathrm{cis}-9(6.3 \%)$, and 18:0 $(7.4 \%)$. The following aldehydes were found: $16: 0(4.4 \%)$ and 18:0 $(3.2 \%)$. And the following dimethyl acetals were found: $16: 0$ (15.4\%), 16:1 cis-9 (2.8\%), 18:0 (8.4\%), 18:1 cis-9 (2.3\%), and $18: 1$ cis-11 (2.1\%).

Biochemical reactions. Resuspended cells from exponentially growing cultures that were tested by using Virginia Polytechnic Institute manual procedures and methods described by Smibert and Krieg (32) were negative for catalase activity, reduction of nitrate to nitrite, the lipase reaction, gelatin liquefaction, hydrolysis of starch, glycogen, or esculin, lecithinase activity, and acid production from glycogen, cellobiose, maltose, fructose, arabinose, glucose, mannose, ribose, xylose, trehalose, and sorbitol; the cells were positive for indole and sulfide formation.

Utilization of amino acids and nitrogenous compounds.
More than $60 \%$ of the free amino acids glycine, arginine, and lysine present in $1 \%$ yeast extract-containing medium were utilized during batch culture of $C$. hydroxybenzoicum. Additions of glycine, L-arginine, and L-lysine, singly and in combinations, to the yeast extract-containing medium had different effects on growth (Table 1) and on the production of volatile fatty acids in growing cultures (Table 2) and concentrated cell suspensions (Table 3). The decreases in aspartate, glutamate, valine, methionine, isoleucine, leucine, and phenylalanine contents observed after growth in the yeast extract-containing medium were not affected significantly by the addition of the amino acids arginine, glycine, and lysine (data not shown). Addition of arginine plus glycine increased the final optical density by more than twofold. When lysine was added to the yeast extract-containing medium, alanine was utilized; and when arginine or glycine or both were added, the alanine and proline contents increased. Also, the serine content increased in cultures supplemented with arginine. Because $C$. hydroxybenzoicum is close to pyrinolytic organisms on the $16 \mathrm{~S}$ rRNA tree, we tested the utilization of uric acid, hypoxanthine, xanthine, guanine, and adenine. However, no significant stimulation of growth was observed when the individual compounds were added at a concentration of $10 \mathrm{mM}$ to the growth medium (44) without additional amino acids.

Influence of sodium and potassium ions and acetic acid on growth. Up to a concentration of $200 \mathrm{mM}$, sodium chloride stimulated and potassium chloride inhibited the growth of $C$. hydroxybenzoicum when these compounds were added to medium containing $0.1 \mathrm{mM}$ sodium ions and $100 \mathrm{mM}$ potassium ions (Fig. 2). Monensin inhibited the growth of $C$. hydroxybenzoicum at a concentration of $1.5 \mu \mathrm{M}(1 \mathrm{ppm})$ or higher (other antibiotics were not tested). Addition of $10 \mathrm{mmol}$ of sodium acetate per liter or $10 \mathrm{mmol}$ of potassium acetate per liter to medium that contained about $80 \mathrm{mM}$ sodium ions and $20 \mathrm{mM}$ potassium ions before the addition resulted in a $45 \%$ increase in growth (Fig. 3A). In contrast, addition of $10 \mathrm{mmol}$ of sodium chloride per liter of medium or $10 \mathrm{mmol}$ of potassium chloride per liter of medium led to only a slight stimulation of growth (Fig. 3A). However, addition of $100 \mathrm{mmol}$ of sodium acetate per liter of medium, $100 \mathrm{mmol}$ of potassium acetate per liter of medium, $100 \mathrm{mmol}$ of sodium chloride per liter of medium, or $100 \mathrm{mmol}$ of potassium chloride per liter of medium had similar stimulatory effects on growth (Fig. 3B).

DNA and RNA analysis. The evolutionary relationships of $C$. hydroxybenzoicum to other clostridia and other species closely related to clostridia as determined by a $16 \mathrm{~S}$ rRNA sequence analysis are shown in Fig. 4 and Table 4 . The three organisms that were most closely related to $C$. hydroxybenzoicum were Clostridium purinolyticum, Clostridium acidiurici, and Clostridium sordellii $(10.6,11.0$, and 15.9 inferred changes per 100 bases, respectively).

As determined by the chemical method of Whitman et al. (37), the DNA base compositions of $C$. hydroxybenzoicum and the type strains of the amino acid-utilizing species $C$. sticklandii and $C$. aminovalericum were $35.5,33.0$, and $35.5 \mathrm{~mol} \% \mathrm{G}+\mathrm{C}$, respectively.

\section{DISCUSSION}

Comparison of $C$. hydroxybenzoicum with similar clostridia. (i) Amino acid utilization. Addition of glycine or glycine plus arginine stimulated the growth of $C$. hydroxybenzoicum (Table 1 ), indicating that glycine (as electron acceptor) and arginine (as electron donor) can function as a pair for a Stickland-like reaction (25). In contrast to the results obtained with other clostridia which use the energy-producing arginine deaminase 

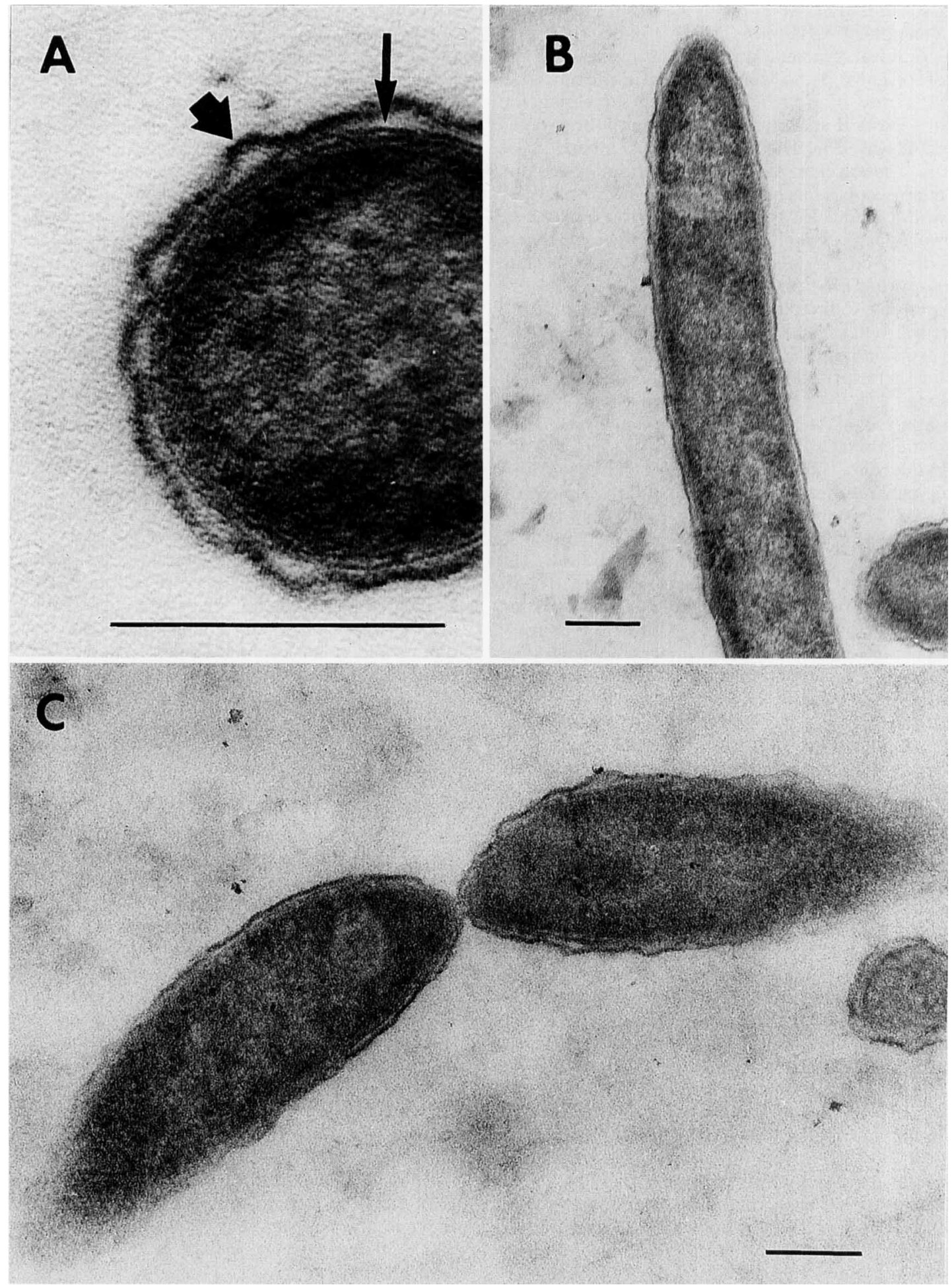

FIG. 1. Transmission electron micrographs of $C$. hydroxybenzoicum cells. Bars $=0.2 \mu \mathrm{m}$. (A) Resolution of the cell wall with an undulating surface layer (thick arrow) and the cytoplasmic membrane (thin arrow) of a cell apparently in the horizontal plane. (B) Typical cell of $C$. hydroxybenzoicum. (C) Last stage of cell division. Note the pointed ends of the cells.

pathway $(8,24,31)$, adding arginine alone to the yeast extractcontaining medium did not stimulate the growth of $C$. hydroxybenzoicum; however, arginine almost completely disappeared from the culture, and about $60 \%$ of the arginine was recovered as ornithine (Table 1). The addition of arginine resulted in decreased growth (Tables 1 and 2), suggesting that uptake of arginine is an ATP-requiring process (35). On the basis of the growth obtained, the utilization of glycine and arginine, and 
TABLE 1. Growth and amino acid utilization in medium with and without added amino acids

\begin{tabular}{|c|c|c|c|c|c|c|}
\hline \multirow{2}{*}{ Addition(s) } & \multirow{2}{*}{ Growth $(\%)^{a}$} & \multicolumn{5}{|c|}{ Concn of amino acids utilized $(\mathrm{mM})^{h}$} \\
\hline & & Ala & Arg & Gly & Lys & Orn \\
\hline None & 100 & 0.7 & 0.7 & 3.2 & 0.1 & 0 \\
\hline L-Arg (6 mmol/liter) & 95 & $+0.5^{c}$ & 7.0 & 3.1 & 0.1 & +4.1 \\
\hline Gly (13 mmol/liter) & 115 & +3.6 & 0.8 & 12.1 & 0.1 & 0 \\
\hline L-Lys ( $7 \mathrm{mmol} / \mathrm{liter})$ & 161 & 4.6 & 0.8 & 3.1 & 9.1 & 0 \\
\hline L-Arg (6 mmol/liter) + Gly (13 mmol/liter) & 215 & +4.5 & 7.0 & 13.3 & 0.1 & 0 \\
\hline L-Arg (6 mmol/liter) + L-Lys (7 mmol/liter) & 144 & 0.1 & 7.0 & 3.1 & 6.7 & +4.1 \\
\hline Gly (13 mmol/liter) + L-Lys (7 mmol/liter) & 204 & 1.5 & 0.8 & 6.5 & 9.1 & 0 \\
\hline
\end{tabular}

${ }^{a}$ A growth value of $100 \%$ was equivalent to an optical density of 0.213 at $600 \mathrm{~nm}$. The growth medium contained $1 \%$ yeast extract

${ }^{b}$ Before the L-arginine, glycine, and L-lysine additions were made, the yeast extract-containing medium also contained the following concentrations of free amino acids: Ala, $10 \mathrm{mM}$; Arg, $1.2 \mathrm{mM}$; Gly, $3.3 \mathrm{mM}$; Lys, $2.2 \mathrm{mM}$; and Orn, $0.3 \mathrm{mM}$. The experimental values were corrected for these zero-time values. The proteins and peptides in the yeast extract-containing medium were not hydrolyzed before the concentrations of the amino acids in the yeast extract-containing medium or the supernatant of a grown culture were determined.

"A plus sign indicates that the amino acid was produced.

the products formed, ornithine seems to act as an electron donor and energy source in C. hydroxybenzoicum, as it does in other amino acid-utilizing clostridia (8). The addition of lysine alone slightly stimulated growth, and butyrate was the major product (Tables 2 and 3). Cell suspensions of $C$. hydroxybenzoicum formed more butyrate than acetate when lysine was added, which indicated that butyrate was produced from acetate or acetyl moieties during lysine catabolism (2). However, a cell suspension supplemented with L-lysine and Larginine did not form more volatile acids than the control (Table 3). This inhibition might have been due in part to the presence of a cotransport system for lysine and arginine (8).

From the data described above it appears that $C$. hydroxybenzoicum is an organism that has the ability to utilize amino acids like other peptidolytic organisms by using Stickland-like reactions.

The fatty acid profile of $C$. hydroxybenzoicum falls into the group of Elsden et al. (11) which contains fatty acids that have mainly odd numbers of carbon atoms, 14:0 acids as the major fatty acids, and no significant amounts of iso and anteiso acids. C. hydroxybenzoicum formed also as main acids the unsaturated acids $16: 1 \mathrm{cis}-9$ and $18: 1 \mathrm{cis}-9$ and the saturated acids 16:0 and 18:0. Thus, the $C$. hydroxybenzoicum pattern does not really match any of the previously described fatty acid patterns. However, the fatty acid patterns of anaerobic gram-positive organisms are apparently very sensitive to variations in physiological state and growth conditions; thus, a quantitative comparison with previously published values and values from other libraries is questionable.

Although the characteristic property of C. hydroxybenzoicum is the transformation of hydroxybenzoate, which is an intermediate in aromatic amino acid utilization in many peptidolytic clostridia, this bacterium does not metabolize aromatic amino acids and does not produce $p$-hydroxyphenyl acids from tyrosine; thus, $C$. hydroxybenzoicum also differs in this respect from physiologically similar peptidolytic and amino acid-utilizing clostridia, including Clostridium sporogenes, Clostridium botulinum (types $\mathrm{A}, \mathrm{B}, \mathrm{F}$, and $\mathrm{G}$ ), Clostridium subterminale, and $C$. sticklandii (10). When $C$. hydroxybenzoicum was compared with the groups suggested by Mead (23), it fit loosely with the organisms in group IIA; $\delta$-aminovalerate is not produced, and arginine and glycine are utilized. This group contains $C$. botulinum and Clostridium histolyticum, but both of these organisms differ from $C$. hydroxybenzoicum in many important properties (Table 5).

The inhibitory effect of monensin on growth and the amino acid utilization combined with the stimulation of $C$. hydroxybenzoicum growth by sodium ions in sodium-deficient medium (Fig. 2) suggests that $C$. hydroxybenzoicum utilizes a sodiumproton antiport and a sodium-amino acid symport(s) $(7,28,40)$.

(ii) $\mathbf{G}+\mathbf{C}$ content and $16 \mathrm{~S}$ rRNA sequence analysis. $C$. hydroxybenzoicum has a DNA base composition of $35.5 \mathrm{~mol} \%$ $\mathrm{G}+\mathrm{C}(44)$, which is similar to the DNA base compositions of several other mesophilic clostridia, including C. sticklandii (31 $\mathrm{mol} \% \mathrm{G}+\mathrm{C}$ as determined by the thermal denaturation method; $33 \mathrm{~mol} \% \mathrm{G}+\mathrm{C}$ as determined by a chemical method [this study]), C. aminovalericum (33 mol\% $\mathrm{G}+\mathrm{C}$ as determined by the thermal denaturation method; $35.5 \mathrm{~mol} \% \mathrm{G}+\mathrm{C}$ as determined by a chemical method [this study]), Clostridium aceticum $(33$ mol\% $\mathrm{G}+\mathrm{C}$ as determined by the thermal denaturation method), Clostridium formicoaceticum (34 mol\% $\mathrm{G}+\mathrm{C}$ as determined by the thermal denaturation method), and Clostridium propionicum (35 mol\%) (6). C. aceticum and C. formicoaceticum are glycolytic homoacetogens; $C$. propionicum

TABLE 2. Growth and volatile fatty acid production in culture medium with and without added amino acids

\begin{tabular}{|c|c|c|c|c|c|c|c|}
\hline \multirow{2}{*}{ Addition(s) } & \multirow{2}{*}{ Growth $(\%)^{a}$} & \multicolumn{6}{|c|}{ Concn of volatile fatty acids produced (mM) } \\
\hline & & Acetate & Propionate & Isobutyrate & Butyrate & Isovalerate & Valerate \\
\hline None & 100 & 2.4 & 0 & 0.2 & 2.1 & 0.2 & 0.03 \\
\hline $\operatorname{Arg}(10 \mathrm{mM})$ & 66 & 2.4 & 0 & 0.1 & 1.2 & 0.1 & 0.03 \\
\hline Gly $(10 \mathrm{mM})$ & 216 & 13.0 & 2.0 & 0.6 & 2.2 & 1.1 & 0.03 \\
\hline Lys $(10 \mathrm{mM})$ & 128 & 3.1 & 1.1 & 0.2 & 12.7 & 0.4 & 0.05 \\
\hline $\operatorname{Arg}(10 \mathrm{mM})+$ Gly $(10 \mathrm{mM})$ & 469 & 16.8 & 1.5 & 0.4 & 1.5 & 0.7 & 0.04 \\
\hline $\operatorname{Arg}(10 \mathrm{mM})+$ Lys $(10 \mathrm{mM})$ & 93 & 3.1 & 1.5 & 0.2 & 17.6 & 0.4 & 0.05 \\
\hline Gly $(10 \mathrm{mM})+$ Lys $(10 \mathrm{mM})$ & 375 & 15.3 & 1.8 & 0.6 & 7.7 & 1.1 & 0.05 \\
\hline
\end{tabular}

${ }^{a}$ A growth value of $100 \%$ was equivalent to an optical density of 0.092 at $600 \mathrm{~nm}$. The mineral medium was supplemented with $0.38 \%$ yeast extract, $0.86 \% \mathrm{NaCl}$, and 20 times the vitamin concentration described previously (36). 
TABLE 3. Utilization of three amino acids and production of volatile fatty acids by a $C$. hydroxybenzoicum cell suspension

\begin{tabular}{|c|c|c|c|c|c|c|c|c|c|c|}
\hline \multirow{2}{*}{ Addition $(\mathrm{s})^{a}$} & \multicolumn{5}{|c|}{ Concn of amino acids utilized (mM) } & \multicolumn{5}{|c|}{ Concn of volatile fatty acids produced (mM) } \\
\hline & $\mathrm{Ala}$ & $\operatorname{Arg}$ & Gly & Lys & Orn & Acetate & Propionate & Isobutyrate & Butyrate & Isovalerate \\
\hline None & 0 & & & & 0 & 0.7 & 0 & 0 & 0.5 & $\operatorname{Tr}$ \\
\hline Arg $(10 \mathrm{mM})$ & 0 & 9.9 & & & $+7.5^{b}$ & 0.9 & 0 & 0 & 0.4 & $\operatorname{Tr}$ \\
\hline Gly $(11 \mathrm{mM})$ & 0 & & 3.5 & & 0 & 5.4 & 0 & 0.14 & 0.3 & 0.19 \\
\hline Lys $(12 \mathrm{mM})$ & 0 & & & 7.5 & 0 & 7.6 & 0.7 & 0.08 & 11.8 & $\operatorname{Tr}$ \\
\hline $\operatorname{Arg}(10 \mathrm{mM})+$ Gly $(10 \mathrm{mM})$ & +1.5 & 10.0 & 10.0 & & +5.3 & 10.6 & 0 & 0.17 & 0.5 & 0.17 \\
\hline $\operatorname{Arg}(10 \mathrm{mM})+\operatorname{Lys}(10 \mathrm{mM})$ & 0 & 9.7 & & & $+6.5^{c}$ & 0.7 & 0 & 0 & 0.6 & $\operatorname{Tr}$ \\
\hline Gly $(11 \mathrm{mM})+$ Lys $(10 \mathrm{mM})$ & 0 & & 4.0 & 1.7 & 0 & 6.9 & 0 & 0.11 & 3.6 & 0.31 \\
\hline
\end{tabular}

${ }^{a}$ The organism was grown on yeast extract-containing medium supplemented with $10 \mathrm{mM}$ glycine, L-arginine, and L-lysine and resuspended in mineral medium lacking any carbon and energy sources. The optical density at $600 \mathrm{~nm}$ of the cell suspension was about 1.3 . After the additions, the cell suspensions were incubated at $30^{\circ} \mathrm{C}$ for $22 \mathrm{~h}$ before the analysis was performed.

${ }^{\prime}$ A plus sign indicates that the amino acid was produced.

since the retention times and coefficient constants of lysine and ornithine are very similar, this value may be less accurate than the other values.

produces propionate as a major fermentation product. The DNA $\mathrm{G}+\mathrm{C}$ content of $C$. aminovalericum is very similar to that of $C$. hydroxybenzoicum, but other properties of these two organisms, such as fermentation products, the ability to decarboxylate hydroxybenzoate, the ability to utilize substrates, and the $16 \mathrm{~S}$ rRNA sequences, are significantly different. Thus, all of these species with similar $\mathrm{G}+\mathrm{C}$ contents are physiologically and phylogenetically different from $C$. hydroxybenzoicum.

On the basis of $16 \mathrm{~S}$ rRNA sequence analysis data, $C$. hydroxybenzoicum is much more closely related to the purinolytic clostridia, $C$. purinolyticum and $C$. acidiurici, than to the typical amino acid utilizers that have similar $\mathrm{G}+\mathrm{C}$ contents $(C$. sticklandii and $C$. aminovalericum) and to other peptidolytic clostridia (27). However, since growth of $C$. hydroxybenzoicum is not stimulated by the addition of $10 \mathrm{mM}$ adenine, hypoxanthine, uric acid, guanine, or xanthine to the medium, $C$. purinolyticum and $C$. acidiurici differ physiologically from $C$. hydroxybenzoicum.

Thus, although the genus Clostridium is very heterogeneous

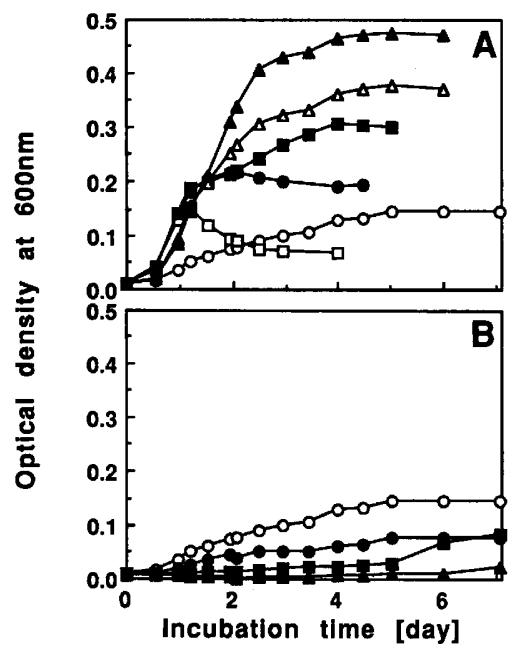

FIG. 2. Effect of sodium ions on the growth of $C$. hydroxybenzoicum. Mineral medium was supplemented with $0.2 \%$ yeast extract, $0.2 \%$ glycine, $0.2 \%$ arginine, and 10 times the vitamin concentration used previously (44). The medium contained $0.1 \mathrm{mM}$ sodium and 100 $\mathrm{mM}$ potassium after inoculation. $\mathrm{NaCl}(\mathrm{A})$ or $\mathrm{KCl}(\mathrm{B})$ was added to the sodium-deficient medium described above at a concentration of 10 $\mathrm{mM}(\bigcirc), 20 \mathrm{mM}(\square), 50 \mathrm{mM}(\boldsymbol{\square}), 100 \mathrm{mM}(\triangle)$, or $200 \mathrm{mM}(\boldsymbol{\Delta}) . \bigcirc$, control (no $\mathrm{NaCl}$ or $\mathrm{KCl}$ added). and the 16S rRNA sequence of $C$. hydroxybenzoicum places it outside the group of species around $C$. butyricum (the type species), which represents clostridia sensu stricto, we place this organism tentatively in a new Clostridium species, $C$. hydroxybenzoicum, until more closely related organisms are identified and rules for reorganization of the genus have been formulated.

Description of Clostridium hydroxybenzoicum sp. nov. Clostridium hydroxybenzoicum (hy. drox. y. ben. zo' i. cum. Gr. $\mathrm{n}$. hydro, water; Gr. n. oxys, acid; N. L. n. hydroxy, water acid; Ger. and Fr, n. benzoin, frankincense of Java; Ger. n. benzoesäure, resin obtained from the tree Styrax benzoin; N. L. adj. hydroxybenzoicum, pertaining to the organic acid hydroxybenzoic acid, referring to the characteristic feature of this organism, the reversible decarboxylation of 4-hydroxybenzoate and 3,4-dihydroxybenzoate) $(42,44)$. Two differently induced decarboxylases are responsible for the reversible decarboxylation of 4-hydroxybenzoate and the decarboxylation of 3,4-dihydroxybenzoate. The use, however, of the decarboxylation products,

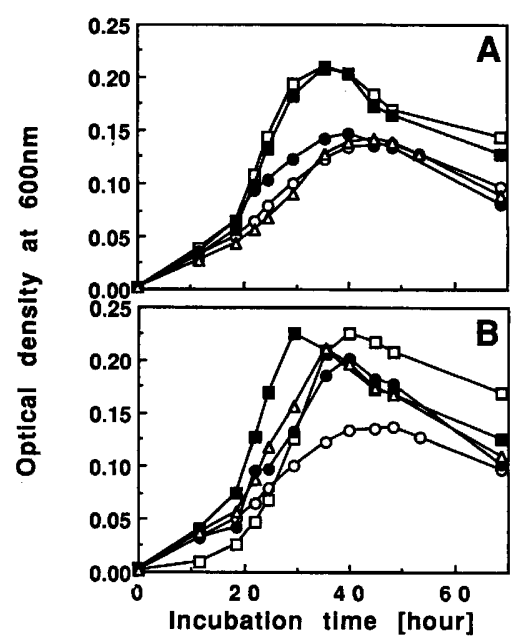

FIG. 3. Effect of acetic acid on the growth of C. hydroxybenzoicum. Mineral medium was supplemented with $1 \%$ yeast extract, 20 times the vitamin concentration used previously (44), $80 \mathrm{mM}$ sodium, and 20 $\mathrm{mM}$ potassium ions. (A) Compounds added at a concentration of 10 mmol per liter of medium. (B) Compounds added at a concentration of $100 \mathrm{mmol}$ per liter of medium. Symbols: $\mathbf{\square}$, sodium acetate; $\boldsymbol{O}$, sodium chloride; $\square$, potassium acetate; $\triangle$, potassium chloride; $\bigcirc$, control. 


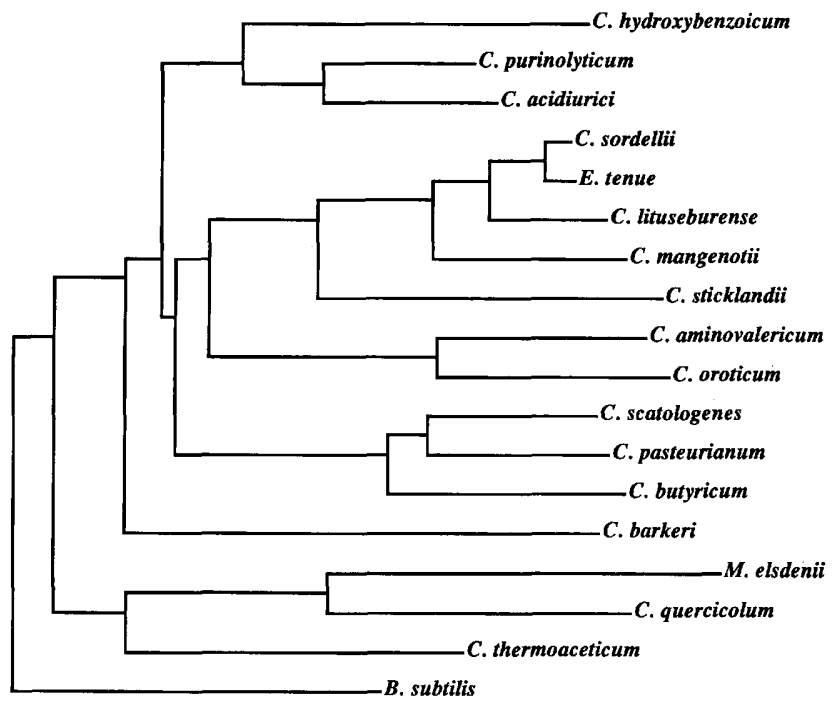

$10 \%$

FIG. 4. Phylogenetic tree for $C$. hydroxybenzoicum and related organisms based on 16S rRNA sequences (see Materials and Methods and Table 4). Bar $=10 \%$ inferred changes per 100 nucleotides. $E$. tenue, Eubacterium tenue; $M$. elsdenii, Megasphaera elsdenii; $B$. subtilis, Bacillus subtilis. B. subtilis was used as an outgroup to root the tree.

e.g., phenol and catechol, as a carbon or energy source by $C$. hydroxybenzoicum was not observed.

C. hydroxybenzoicum cells are strictly anaerobic, slightly curved rods that are 0.35 to $0.76 \mu \mathrm{m}$ in diameter and 2.5 to 5.1 $\mu \mathrm{m}$ long, depending on the growth conditions and the growth stage. The organism is nonmotile, and no flagella have been observed in negatively stained cells by use of an electron microscope. Sporulating cells elongate to between 5.0 and 8.0 $\mu \mathrm{m}$ long and produce terminal swollen sporangia (drumstick type). Spores are round to slightly oval (diameter, 0.8 to 1.1 $\mu \mathrm{m})$. The Gram reaction of the cells from the early to late exponential growth phase is negative. However, lipopolysaccharides are not detected, indicating that the organism is gram positive. The cell wall type is $\mathrm{A} 1 \alpha$ (L-Lys direct).

The $\mathrm{pH}$ supporting growth ranges from 6.1 to 10 , and the optimal $\mathrm{pH}$ is 7.2 to 8.2 . The temperature range for growth is 12 to $41^{\circ} \mathrm{C}$, and the optimal temperature is 33 to $34^{\circ} \mathrm{C}$.

C. hydroxybenzoicum requires yeast extract for growth. Acetic acid and sodium ions at concentrations of up to 10 and 200 $\mathrm{mM}$, respectively, stimulate growth, whereas $5 \% \mathrm{NaCl}$ completely inhibits growth. Neither $\mathrm{CO}_{2}-\mathrm{HCO}_{3}{ }^{-}$nor sulfide is required for growth; addition of nitrate, sulfate, or thiosulfate has no effect on growth. During growth in mineral medium containing $1.5 \%$ yeast extract and $200 \mathrm{mM}$ acetate, $5 \mathrm{mM}$ butyrate, $4 \mathrm{mM}$ isovalerate, $1 \mathrm{mM}$ propionate, $1 \mathrm{mM}$ isobutyrate, $0.2 \mathrm{mM}$ isopentanol, and traces of valerate are formed, but $\mathrm{H}_{2}$ is not formed. Addition of $0.1 \%$ each of glycine, arginine, and lysine to yeast extract-containing medium stimulates growth three- to fivefold. Carbohydrates are not fermented; there is no significant acid formation from carbohydrates by resting cells. Addition of $\mathrm{H}_{2}$ plus $\mathrm{CO}_{2}$, ethanol, propanol, isobutanol, propionic acid, butyric acid, isobutyric acid, valeric acid, pyruvic acid, lactic acid, uric acid, adenine, hypoxanthine, guanine, or xanthine does not stimulate growth.

Tests for catalase activity, reduction of nitrate to nitrite, lipase activity, gelatin liquefaction, hydrolysis of starch, glycogen, or esculin, and lecithinase activity are negative; tests for indole and sulfide formation are positive.

The DNA base composition is $35.5 \mathrm{~mol} \% \mathrm{G}+\mathrm{C}$ (as determined by the chemical method).

So far, $C$. hydroxybenzoicum has been enriched and isolated only from methanogenic sediment from a freshwater pond in Athens, Ga.

TABLE 4. Evolutionary distances between $C$. hydroxybenzoicum and organisms that are members of the clostridial subphylum

Evolutionary distance

\begin{tabular}{|c|c|c|c|c|c|c|c|c|c|c|c|c|c|c|c|c|c|}
\hline Organism & 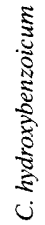 & 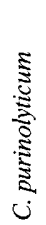 & نَّ & 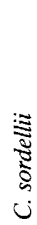 & 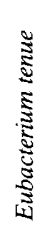 & 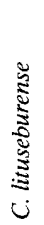 & 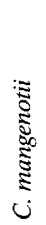 & ن & 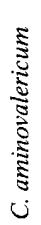 & 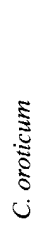 & 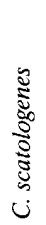 & 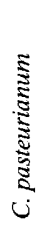 & 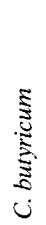 & U. & 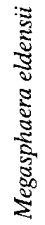 & 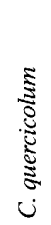 & 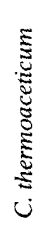 \\
\hline
\end{tabular}

\begin{tabular}{|c|c|c|c|c|c|c|c|c|c|c|c|c|c|c|c|c|c|}
\hline C. purinolyticum & 10.9 & & & & & & & & & & & & & & & & \\
\hline C. acidiurici & 11.6 & 6.2 & & & & & & & & & & & & & & & \\
\hline C. sordellii & 16.0 & 12.9 & 13.4 & & & & & & & & & & & & & & \\
\hline Eubacterium tenue & 15.8 & 13.0 & 13.4 & 1.0 & & & & & & & & & & & & & \\
\hline C. lituseburense & 17.3 & 13.4 & 14.3 & 3.7 & 4.0 & & & & & & & & & & & & \\
\hline C. mangenotii & 17.1 & 15.4 & 14.7 & 6.3 & 6.5 & 7.1 & & & & & & & & & & & \\
\hline C. sticklandii & 18.0 & 15.9 & 16.3 & 10.8 & 10.8 & 12.7 & 13.5 & & & & & & & & & & \\
\hline C. aminovalericum & 16.8 & 15.6 & 15.6 & 15.1 & 15.9 & 15.4 & 16.6 & 17.4 & & & & & & & & & \\
\hline C. oroticum & 17.8 & 17.3 & 16.5 & 15.0 & 15.6 & 16.3 & 16.5 & 18.1 & 8.5 & & & & & & & & \\
\hline C. scatologenes & 17.4 & 15.5 & 16.0 & 15.4 & 15.5 & 16.3 & 16.8 & 17.2 & 18.0 & 17.6 & & & & & & & \\
\hline C. pasteurianum & 16.1 & 14.2 & 14.9 & 16.5 & 16.8 & 17.8 & 18.0 & 17.6 & 18.0 & 17.9 & 6.0 & & & & & & \\
\hline C. butyricum & 17.1 & 15.1 & 15.8 & 17.1 & 17.5 & 17.0 & 16.9 & 18.4 & 18.0 & 17.3 & 8.6 & 8.0 & & & & & \\
\hline C. barkeri & 16.7 & 14.9 & 14.3 & 18.2 & 17.9 & 18.8 & 18.2 & 20.0 & 19.5 & 20.5 & 18.3 & 17.4 & 19.1 & & & & \\
\hline Megasphaera elsdenii & 22.8 & 20.1 & 22.8 & 22.9 & 23.4 & 22.6 & 25.3 & 22.4 & 22.2 & 22.6 & 23.1 & 22.2 & 23.8 & 23.9 & & & \\
\hline C. quercicolum & 20.7 & 18.2 & 20.0 & 20.9 & 21.0 & 21.1 & 20.9 & 23.1 & 21.7 & 22.6 & 22.4 & 21.2 & 23.0 & 21.2 & 13.2 & & \\
\hline C. thermoaceticum & 17.6 & 16.4 & 16.6 & 17.6 & 17.5 & 18.3 & 18.2 & 18.4 & 19.4 & 19.5 & 18.1 & 17.7 & 19.2 & 18.0 & 17.6 & 16.4 & \\
\hline Bacillus subtilis & 19.3 & 16.5 & 16.2 & 18.1 & 17.9 & 18.6 & 18.7 & 19.6 & 19.5 & 19.8 & 17.3 & 16.0 & 18.0 & 17.4 & 21.3 & 18.0 & 15.7 \\
\hline
\end{tabular}




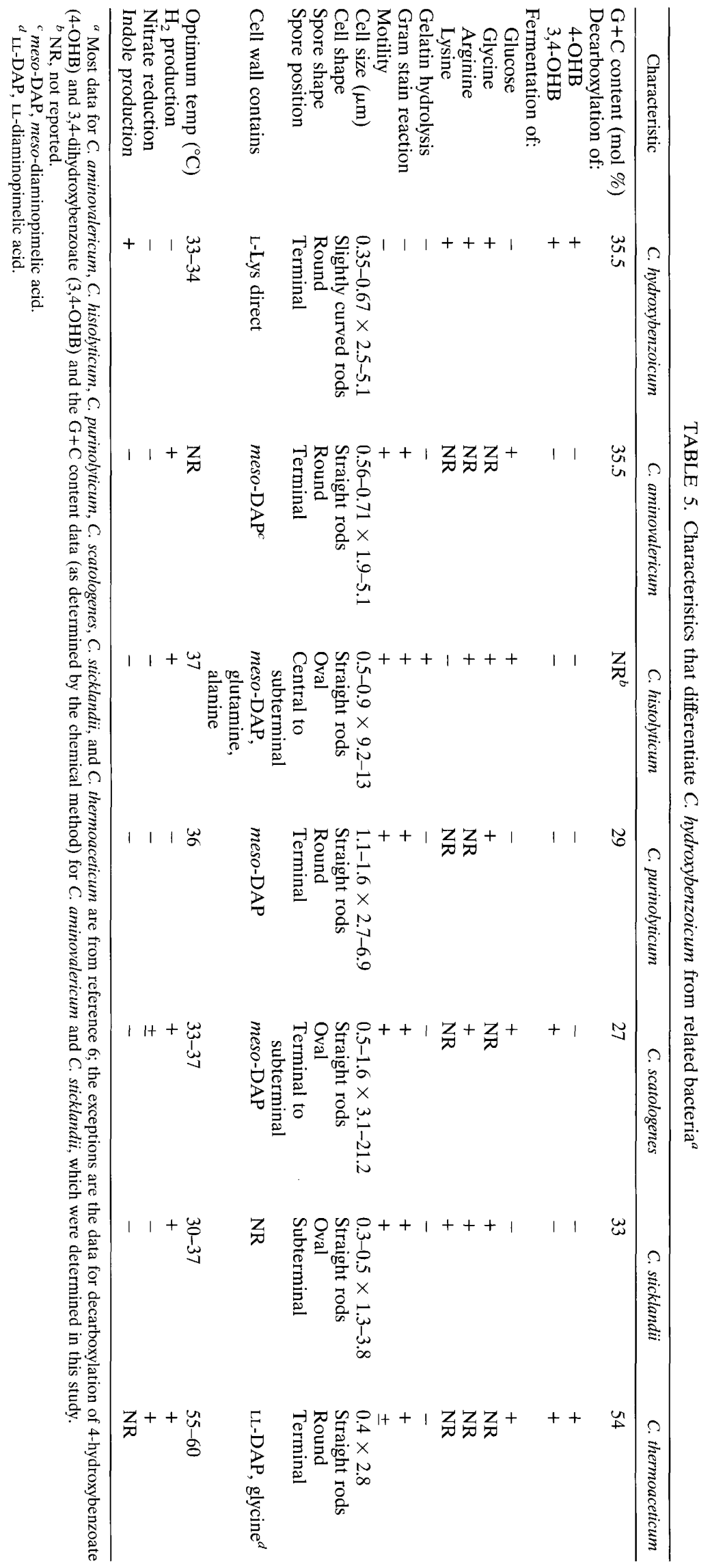


Type strain. Strain JW/Z-1 is the type strain of $C$. hydroxybenzoicum ATCC $51151=$ DSM 7310. The G+C content of this strain is $35.5 \mathrm{~mol} \%$, and the accession number of its $16 \mathrm{~S}$ rRNA is L11305. The properties of the type strain are the same as those described above for the species.

\section{ACKNOWLEDGMENTS}

This work was supported in the beginning by Department of Energy grant DE-FG 09-86 ER13614 and later by U.S. Office of Naval Research grant N00014-91-J1874.

We are indebted to W. B. Whitman for the use of his facilities for the DNA $\mathrm{G}+\mathrm{C}$ content determination, to $\mathrm{N}$. Weiss (Deutsche Sammlung von Mikroorganismen and Zellkulturen) for the cell wall analysis, and to B. C. Hemming for help with the fatty acid analysis. We thank W. J. Payne for editorial help.

\section{REFERENCES}

1. American Type Culture Collection. 1989. Catalogue of bacteria and bacteriophages, 17th ed. American Type Culture Collection, Rockville, Md.

2. Barker, H. A. 1981. Amino acid degradation by anaerobic bacteria. Annu. Rev. Biochem. 50:23-40.

3. Bayer, E., E. Grom, B. Kaltenegger, and R. Uhmann. 1976. Separation of amino acids by high performance liquid chromatography. Anal. Chem. 48:1106-1109.

4. Berry, D. F., A. J. Francis, and J. M. Bollag. 1987. Microbial metabolism of homocyclic and heterocyclic aromatic compounds under anaerobic conditions. Microbiol. Rev. 51:43-49.

5. Biggin, M. D., T. J. Gibson, and G. F. Hing. 1983. Buffer gradient gels and ${ }^{35} \mathrm{~S}$ label as an aid to rapid DNA sequence determination. Proc. Natl. Acad. Sci. USA 89:3936-3965.

6. Cato, E. P., W. L. George, and S. M. Finegold. 1986. Clostridium Prazmowski $1880,23^{\mathrm{AL}}$, p. $1141-1200$. In P. H. A. Sneath, N. S. Mair, M. E. Sharpe, and J. G. Holt (ed.), Bergey's manual of systematic bacteriology, vol. 2. The Williams \& Wilkins Co., Baltimore.

7. Chen, G., and J. B. Russell. 1989. Sodium-dependent transport of branched-chain amino acids by a monensin-sensitive ruminal Peptostreptococcus. Appl. Environ. Microbiol. 55:2658-2663.

8. Cunin, R., N. Glansdorff, A. Pierard, and V. Stalon. 1986. Biosynthesis and metabolism of arginine in bacteria. Microbiol. Rev. 50:314-352.

9. De Soeto, G. 1983. A least square algorithm for fitting additive trees to proximity data. Psychometrika 48:621-626.

10. Elsden, S. R., and M. G. Hilton. 1979. Amino acid utilization patterns in clostridial taxonomy. Arch. Microbiol. 123:137-141.

11. Elsden, S. R., M. G. Hilton, K. R. Parsley, and R. Self. 1980. The lipid fatty acids of proteolytic clostridia. J. Gen. Microbiol. 118: $115-123$.

12. Evans, W. C., and G. Fuchs. 1988. Anaerobic degradation of aromatic compounds. Annu. Rev. Microbiol. 42:289-317.

13. Frasca, J. M., and V. R. Parks. 1965. A routine technique for double-staining ultrathin sections using uranyl and lead salts. J. Cell Biol. 25:157-161

14. Genthner, B. R. S., G. T. Townsend, and P. J. Chapman. 1990. Effect of fluorinated analogues of phenol and hydroxybenzoates on the anaerobic transformation of phenol to benzoate. Biodegradation 1:65-74.

15. Haggblom, M. 1990. Mechanisms of bacterial degradation and transformation of chlorinated compounds. J. Basic Microbiol. 30:115-141.

16. Hale, D. D., W. Reineke, and J. Wiegel. Chlorophenol degradation. In G. R. Chaudry (ed.), Biological degradation and bioremediation technologies of toxic chemicals, in press. Timber Press, Portland, Oreg.

17. Hippe, H., J. R. Andreesen, and G. Gottschalk. The genus Clostridium-nonmedical, p. 1800-1866. In A. Balows, H. G. Trüper, M. Dworkin, W. Harder, and K.-H. Schleifer (ed.), The prokaryotes. Springer-Verlag, New York.

18. Jukes, T. H., and C. R. Cantor. 1969. Evolution of protein molecules, p. 21-132. In H. N. Munro (ed.), Mammalian protein metabolism. Academic Press, New York.
19. Kaneda, N., M. Sato, and K. Yagi. 1982. Analysis of dansyl amino acids by reversed-phase high-performance liquid chromatography. Anal. Biochem. 127:49-54.

20. Kellenberger, E., A. Ryter, and J. Sechaud. 1958. Electron microscope study of DNA-containing plasma. II. Vegetative and mature phage DNA as compared with normal bacterial nucleosides in different physiological states. J. Biophys. Biochem. Cytol. 4:671678.

21. Lane, D. J., B. Pace, G. J. Olsen, and D. A. Stahl. 1985. Rapid determination of $16 \mathrm{~S}$ ribosomal RNA sequences for phylogenetic analyses. Proc. Natl. Acad. Sci. USA 82:6955-6959.

22. Marmur, J. 1961. A procedure for the isolation of deoxyribonucleic acid from microorganisms. J. Mol. Biol. 3:208-218.

23. Mead, G. C. 1971. The amino acid fermenting clostridia. J. Gen. Microbiol. 67:47-56.

24. Mitruka, B. M., and R. N. Costilow. 1967. Arginine and ornithine catabolism by Clostridium botulinum. J. Bacteriol. 93:295-301.

25. Nisman, B. 1954. The Stickland reaction. Bacteriol. Rev. 18:16-42.

26. Olsen, G. J., R. Overbeek, N. Larsen, T. L. Marsh, M. J. McCaughey, M. A. Maciukenas, W. M. Kuan, T. J. Macke, and C. R. Woese. 1992. The ribosomal database project. Nucleic Acids Res. 20(Suppl.):2199-2200.

27. Paster, B. J., J. B. Russell, C. M. J. Yang, J. M. Chow, C. R. Woese, and R. Tanner. 1993. Phylogeny of ammonia-producing ruminal bacteria Peptostreptococcus anaerobius, Clostridium sticklandii, and Clostridium aminophilum sp. nov. Int. J. Syst. Bacteriol. 43:107110

28. Russell, J. B. 1987. A proposed mechanism of monensin action in inhibiting ruminal bacterial growth: effects on ion flux and protonmotive force. J. Anim. Sci. 64:1519-1525.

29. Sanger, F., S. Nicklen, and A. R. Coulson. 1977. DNA sequencing with chain-terminating inhibitors. Proc. Natl. Acad. Sci. USA 74:5463-5467.

30. Schleifer, K. H., and O. Kandler. 1972. Peptidoglycan types of bacterial cell walls and their taxonomic implications. Bacteriol. Rev. 36:407-477.

31. Schmidt, G. C., M. A. Logan, and A. A. Tytell. 1952. The degradation of arginine by Clostridium perfringens (BP6K). J. Biol. Chem. 198:771-783.

32. Smibert, R. M., and N. R. Krieg. 1981. General characterization, p. 409-443. In P. Gerhardt, R. G. E. Murray, R. N. Costilow, E. W. Nester, W. A. Wood, N. R. Krieg, and G. B. Phillips (ed.), Manual of methods for general bacteriology. American Society for Microbiology, Washington, D.C.

33. Spurr, A. R. 1969. A low-viscosity epoxy resin embedding medium for electron microscopy. J. Ultrastruct. Res. 26:31-43.

34. Tapuhi, Y., D. E. Schmidt, W. Lindner, and B. L. Karger. 1981. Dansylation of amino acids for high-performance liquid chromatography analysis. Anal. Biochem. 115:123-129.

35. Van Kessel, J. S., and J. B. Russell. 1992. Energetics of arginine and lysine transport by whole cells and membrane vesicles of strain SR, a monensin-sensitive ruminal bacterium. Appl. Environ. Microbiol. 58:969-975.

36. Weisburg, W. G., J. G. Tully, D. L. Rose, J. P. Petzel, H. Oyaizu, D. Yang, L. Mandelco, J. Sechrest, T. G. Lawrence, J. vanEtten, J. Maniloff, and C. R. Woese. 1989. A phylogenetic analysis of the mycoplasmas: basis for their classification. J. Bacteriol. 171:64556467.

36a.Weiss, N. Personal communication.

37. Whitman, W. B., S. Jersong, S. Sohn, D. S. Caras, and U. Premachandran. 1986. Isolation and characterization of 22 mesophilic methanococci. Syst. Appl. Microbiol. 7:235-240.

38. Woese, C. R., R. Gutell, R. Gupta, and H. F. Noller. 1983. Detailed analysis of the higher-order structure of 16S-like ribosomal ribonucleic acids. Microbiol. Rev. 47:621-669.

39. Woese, C. R., M. Sogin, D. A. Stahl, B. J. Lewis, and L. Bonen. 1976. A comparison of the 16 S ribosomal RNAs from mesophilic and thermophilic bacilli. J. Mol. Evol. 7:197-213.

40. Yamato, I., and Y. Anraku. 1990. Mechanism of $\mathrm{Na}^{+}$/proline symport in Escherichia coli: reappraisal of the effect of cation binding to the $\mathrm{Na}^{+} /$proline symport carrier. J. Membr. Biol. 114:143-151. 
41. Young, L. Y. 1984. Anaerobic degradation of aromatic compounds, p. 487-523. In D. E. Gibson (ed.), Microbial degradation of organic compounds. Marcel Dekker, New York.

42. Zhang, X., R. L. Gherna, and J. Wiegel. 1992. Decarboxylation of hydroxybenzoate by strictly anaerobic bacteria in methanogenic sediments and pure cultures, p. 498-504. In DECHEMA, Proceedings of the International Symposium on Soil Decontamination Using Biological Processes, Karlsruhe.

43. Zhang, X., T. V. Morgan, and J. Wiegel. 1990. Conversion of ${ }^{13} \mathrm{C}-1$ phenol to ${ }^{13} \mathrm{C}-4$ benzoate, an intermediate in the anaerobic degradation of chlorophenols. FEMS Lett. 67:63-66.

44. Zhang, X., and J. Wiegel. 1990. Isolation and partial characterization of a Clostridium species transforming para-hydroxybenzoate and 3,4-dihydroxybenzoate and producing phenols as the final transformation products. Microb. Ecol. 20:103-121.

45. Zhang, X., and J. Wiegel. 1990. Sequential anaerobic degradation of 2,4-dichlorophenol in freshwater sediments. Appl. Environ. Microbiol. 56:1119-1127. 